\title{
Impact of UV radiation on DOM transformation on molecular level using FT-ICR-MS and PARAFAC
}

\author{
Mario L. Miranda ${ }^{\mathrm{a}, \mathrm{b}, *}$, H. Osterholz ${ }^{\mathrm{c}, \mathrm{d}}$, H.-A. Giebel ${ }^{\mathrm{e}}$, P. Bruhnke ${ }^{\mathrm{c}}$, T. Dittmar $^{\mathrm{c}, \mathrm{f}}$, O. Zielinski ${ }^{\text {a,g }}$ \\ a Marine Sensor Systems Group, Institute for Chemistry and Biology of the Marine Environment (ICBM), University of Oldenburg, 26382, Wilhelmshaven, Germany \\ b Laboratorio de la Calidad del Aire y Agua (LACAYA), El Cangrejo, Universidad de Panamá, 0824, Panamá. \\ ' ICBM-MPI Bridging Group for Marine Geochemistry, Institute for Chemistry and Biology of the Marine Environment, University of Oldenburg, 26129 Oldenburg, Germany \\ d Department of Marine Chemistry, Leibniz-Institute for Baltic Sea Research (IOW), Rostock 18119, Germany \\ e Biology of Geological Processes Group, Institute for Chemistry and Biology of the Marine Environment (ICBM), University of Oldenburg, 26129 Oldenburg, Germany \\ ${ }^{\mathrm{f}}$ Helmholtz Institute for Functional Marine Biodiversity at the University of Oldenburg (HIFMB), Oldenburg 26129, Germany \\ ${ }^{g}$ Marine Perception Research Group, German Research Center for Artifical Intelligence (DFKI), 26129 Oldenburg, Germany
}

\section{A R T I C L E I N F O}

\section{Article history:}

Received 30 July 2019

Received in revised form 17 December 2019

Accepted 2 January 2020

Available online 7 January 2020

\section{Keywords:}

Fluorescent dissolved organic matter

Refractory dissolved organic matter

Ultraviolet radiation

Recent produced materials index

Fourier-transform ion cyclotron mass spec-

trometry

Parallel factor analysis

Photodegradation

\begin{abstract}
A B S T R A C T
Dissolved organic matter (DOM) is an omnipresent constituent of natural water bodies. Reuse and transformation of DOM compounds in the water column is driven by physicochemical and biological processes leading to the production of refractory DOM. Typically, breakdown of DOM chemical compounds into smaller or more condensed fragments is triggered by ultraviolet (UV) radiation. Here, we present a study on the photodegradation of DOM produced during an incubation experiment with a natural microbial community. At the end of the first incubation without UV irradiation, the samples from 3 mesocosms were filtered to remove microbes and particles and continuously exposed to UV radiation (280-365 nm). We investigated DOM in depth via monitoring of dissolved organic carbon (DOC) concentrations, DOM molecular characterization by Fourier-Transform Ion Cyclotron Resonance Mass Spectrometry (FT-ICR-MS) and excitation emission matrix spectroscopy (EEMS). Analysis of variance indicated no significant differences in the DOC concentration between treatments. Main peaks in the fluorescent DOM (FDOM) were photo-bleached by UV radiation, and an increase in the fluorescent intensity of selected peaks was observed on irradiated samples toward the end of the experiment. Parallel factor analysis (PARAFAC) indicated the presence of three main components in all treatments: C1 (Marine humic M), C2 (Bacterial produced humic C), C3 (Tyrosine), and an additional component in the dark incubation of mesocosm 3, C4 (Tryptophan). Despite an intensive filtration protocol through 0.7, 0.2 and $0.1 \mu \mathrm{m}$ filters, low bacterial abundances were determined $\left(<2.5 \times 10^{-3}\right.$ cells $\left.\mathrm{mL}^{-1}\right)$. We observed a direct correlation between structural indices and the intensity of PARAFAC components. Average double bond equivalent and aromaticity were strongly positively correlated with PARAFAC components C1 and C2 for one or more mesocosm. Moreover, FT-ICR-MS showed that under the tested conditions, the refractory character of the DOM assessed as the similarity to a deep ocean DOM reference did not increase on molecular level. Thus, mechanisms other than photochemical transformations of relatively recent DOM are likely necessary to facilitate long-term stability of DOM in the oceans.
\end{abstract}

@ 2020 Published by Elsevier B.V.

\section{Introduction}

Dissolved Organic Matter (DOM) is an omnipresent component of the oceans and recent calculations estimate that marine DOM contains approximately $685 \mathrm{Pg} \mathrm{C}$, equivalent to the inorganic carbon contained by the atmosphere [1]. The composition of DOM in natural waters strongly depends on region-specific inputs as well as autochthonous

* Corresponding author at: Marine Sensor Systems Group, Institute for Chemistry and Biology of the Marine Environment (ICBM), University of Oldenburg, 26382 Wilhelmshaven, Germany.

E-mail address: mario.luis.miranda.montenegro@uni-oldenburg.de (M.L. Miranda). sources. In general, it includes a wide variety of residues such as lignin, humic acids, fulvic acids, proteins, carbohydrates, amino acids, and carboxylic acids [2-6]. The residence time of DOM in the oceans is a key factor for the budget and fluxes of carbon in the environment [7]. The upper layer of the ocean is highly dynamic due to ambient light driving various physical and biological processes that transform DOM [8-11]. A direct link was identified in the sea surface microlayer between the growth of autotrophic organisms and the amount of photosynthetically available radiation (PAR) as well as apparent reuse of photodegraded DOM fractions [12-14]. A rising number of studies have investigated degradation mechanisms leading to the production of recalcitrant DOM [15-19] and its persistence especially in oceanic deep waters. 
Here, specific limitations through environmental conditions, intrinsic stability of compounds possibly also facilitated by photochemical transformations or extreme dilution hindering microbial use may play an important role $[18,20]$.

At the sea surface, one of the main mechanisms of DOM degradation is triggered by ultraviolet (UV) radiation. The photodegradation of DOM in the surface waters suggests the partial destruction of fluorescent structures in chemical compounds and smaller molecules are released into the surrounding environment. It has been reported that the destruction of complex structures such as humic acids and proteins produces compounds of lower molecular weight (LMW) and simpler structures [21,22]. The production of LMW compounds acts as a source of carbon and energy for heterotrophic microorganisms in the oceans, contributing to the reprocessing of DOM [23]. Conversion of LMW DOM into refractory DOM has also been explained through the condensation reactions hypothesis [24]. Additionally, biopolymers such as polysaccharides make up a larger fraction of HMW DOM, explaining its greater lability compared against LMW DOM [25]. Therefore, the conversion of DOM into more refractory compounds is likely accomplished through the intensive exposure to UV radiation, thermal induced reactions, condensation reactions and microbiological recycling processes $[12,18,19,26]$.

DOM composition and transformation can be followed on molecular level by FT-ICR-MS, a technique which is widely used to discriminate and characterize individual molecular formulae or molecule classes in DOM. Structural indices derived from molecular formula information such as double bound equivalent (DBE) and modified aromaticity index (AImod) have recently been used to establish the aromaticity and complexity of photodegraded DOM [27-31]. Linking the complementary information derived from molecular diversity of DOM and the optical and spectroscopic characteristics of identified compounds clarifies the correlation between molecular formula level and FDOM fingerprint fractions and can thus provide a more complete picture of DOM transformations [32].

Optical properties resulting from DOM-light interactions allow for the development of a number of methodologies to better study DOM composition. A typical laboratory based approach is the analysis of excitation-emission matrices spectra (EEMs) that is based on spectroscopic analysis of FDOM. These capabilities can be enhanced by implementing in situ EEMS measurements. Recently development of new in situ sensor called "the kallemeter" was reported, which is capable to produce EEMs with an acceptable degree of resolution. In the near future improvements on this device will strengthen the researchers ability follow DOM transformations avoiding storage time [33]. Sources and transformations of DOM compounds in a sample can be determined as a function of the location of specific peaks in EEMs of the main fluorescent components [2,34]. Among the advantages derived from the use of the excitation-emission matrix spectroscopy (EEMS), in samples exempted of the inner filter effect, is the good correlation between the emission intensity and the concentration of the fluorescent group [35-37]. The correlation between the fluorophore concentration and emission intensity has been used to track the fate, stability, reuse and transformation of fluorescent compounds in diverse aquatic environments $[12,38,39]$. Robust quantitative biogeochemical indices have been proposed and validated to better understand FDOM dynamics in the environment. Here, we use the recent produced material index (REPIX) and the slope coefficient $\left(S_{275-295}\right)$ to follow the photodegradation and reprocessing of FDOM. The $S_{275-295}$ is a good proxy for the molecular weight of DOM fractions. The absorption of LMW compounds is associated with the changes in the absorption coefficient in the wavelength interval between 275 and $295 \mathrm{~nm}$ [40]. Further, EEMS produce a three dimensional array combining measurements of emission, excitation and fluorescent intensity of a sample. Through parallel factor analysis (PARAFAC), independent underlying FDOM components can be derived from the total fluorescent spectra. The sophisticated technique decomposes EEMs datasets in main fluorescent components as function of specific parameters such as leverage scores, emission intensity, and residuals values [41-43].

In this study, we characterized changes in the fluorescent spectra and molecular composition of in situ produced DOM in order to determine if more recently produced DOM becomes more similar to refractory deep sea DOM on molecular level after continuous UV irradiation.

\section{Methodology}

\subsection{Samples source and preparation}

In the previous study [15], a natural coastal microbial community was incubated in low-DOC artificial seawater in order to quantify the production of refractory DOM during a long-term batch incubation. In the present study, we used the DOM produced in three replicate mesocosms (M1, M2, and M3) from the previous experiment. The samples used in the present study were obtained after a 1011 days of incubation without UV radiation. Samples were filtered through glass fiber filters to remove suspended solids. Sequential filtration was completed through a Millipore GTTP Isopore membrane filter with a pore size of $0.2 \mu \mathrm{m}$ and a Sartorius Minisart high-flow syringe filter with a polyether sulfone membrane of $0.1 \mu \mathrm{m}$ pore size. We filled 6 replicate quartz tubes and 6 replicate borosilicate tubes with $75 \mathrm{~mL}$ of the filtered samples for each mesocosm. Additionally, we filled ten tubes with $75 \mathrm{~mL}$ of ultrapure water (MilliQ, arium 611VF, Satorius Stedim Biotech) which served as controls for light and dark treatments. Samples were labeled to indicate source mesocosm (M1, M2, M3), continuous light or dark treatment (L, D) and day of incubation (0 to 30). The borosilicate tubes were used as dark control and wrapped with aluminum foil to prevent changes in DOM due to photodecomposition. Each tube was sealed with a Teflon septum, sufficient headspace ensured oxic conditions. The incubation tubes were placed randomly in a water bath using a support to keep them in a fixed position under water at approximately $10 \mathrm{~cm}$ depth. Water in the open tank was recirculated allowing a uniform temperature distribution. Sampling was carried out at day $0,3,7,11,18$ and 30 by processing one irradiated sample and a dark control for each mesocosm and control. All materials used where precombusted if possible $\left(4 \mathrm{~h}, 400{ }^{\circ} \mathrm{C}\right)$ or thoroughly rinsed with ultrapure water at $\mathrm{pH} 2$ before use.

\subsection{Irradiation chamber design}

A custom-made UV irradiation chamber with black plexigas layers was used to minimize outside UV light contamination. The top of the chamber was equipped with eight UVA 340 fluorescent tubes (Q-Lab Co., Saarbrücken, Germany) as UV radiation source. The light source has been shown to be appropriate for simulating natural UV light in the range from 280 to $365 \mathrm{~nm}[28,44]$. Water temperature and light intensity were recorded with a Hobo Pendant and Onset Hobo data loggers (Melbourne, Australia). Average temperature was $21.5^{\circ} \mathrm{C}$ and light intensity was 616.27 Lumen.

\subsection{Bacterial cell numbers}

Subsamples for the determination of bacterial cell numbers were preserved using glutaraldehyde ( $1 \%$ f.c.) and stored frozen at $-20{ }^{\circ} \mathrm{C}$ until further analysis. Cell numbers of the free-living bacterial cells were counted by flow cytometry using a BD Biosciences Accuri C6 cytometer after DNA-staining using SybrGreen I (Invitrogen) and internal fluidic calibration of the device as described in detail by [45]. Uncertainties associated to this technique have been reported to be lower than $4.2 \%[46]$. 


\subsection{Dissolved organic carbon (DOC)}

Samples were acidified to $\mathrm{pH} 2$ ( $\mathrm{HCl}$, Carl Roth $25 \%$ p.a.). Samples were sealed and stored at $4{ }^{\circ} \mathrm{C}$ in the dark until analysis. DOC determination was performed via high temperature catalytic combustion using a Shimadzu TOC-VCPH/CPN Total Organic Carbon Analyzer (Kyoto, Japan) equipped with an ASI-V auto sampler and a TNM-1 module. Calibration was completed using a standard dissolution of L-Arginine. A deep sea reference (DSR) water sample from the Hansell laboratory at University of Miami was used as reference material to determine precision and accuracy which were better than $5 \%$ and $8 \%$, respectively.

\subsection{EEMS analysis}

Spectrofluorometric measurements were completed within 24 to $72 \mathrm{~h}$ after sampling using a $1 \mathrm{~cm}$ quartz cuvette with a Horiba Aqualog spectrofluorometer (Kyoto, Japan). Three dimensional fluorescence spectra of samples and MilliQ water were determined at $10 \mathrm{~nm}$ bandwidth for both excitation and emission measurements. Excitation wavelengths were scanned in a spectral range of $200 \mathrm{~nm}$ to $500 \mathrm{~nm}$ and two $\mathrm{nm}$ interval. Fluorescence intensity was measured over a wavelength range of $200 \mathrm{~nm}$ to $600 \mathrm{~nm}$, with a $1.617 \mathrm{~nm}$ pre-established intervals. EEMS were corrected using the DrEEM tool box according to [41]. FDOM peak selection was performed as described by Coble [47] in Matlab2015b, using an in-house script.

\subsection{CDOM and absorption coefficients}

We measured the absorbance optical density (OD) and fluorescence properties of dissolved organic matter with a Horiba Aqualog spectrofluorometer (Kyoto, Japan) within a wavelength range of $240-500 \mathrm{~nm}$ in $2 \mathrm{~nm}$ intervals. Quartz cuvettes with $1 \mathrm{~cm}$ path length were rinsed in a $1 \%$ Hellmanex solution to remove organic residues followed by deionized (DI) water. The samples were placed in a water bath at $20^{\circ} \mathrm{C}$ in order to prevent deviations due to temperature changes during measurements. The absorption coefficient was calculated for all samples in dark and light incubations [40]. The spectral slope $S_{275-295}$ of CDOM was derived by an exponential fit between 275 and $295 \mathrm{~nm}$ to the absorption coefficient [8].

\subsection{Recent produced material index (REPIX)}

REPIX has been defined as the ratio of the sum of signal intensities from M-like and T-like fluorophores, associated to the production or transformation of protein-like FDOM of microbial origin, divided by the summation of the signal intensities for humic A-like and humic Clike fractions [48],

$\mathbf{R E P I X}=($ intensity $(M+T)) /($ intensity $(A+C))$

REPIX values $>1$ suggest a predominance of autochthonous FDOM due to the increase in microbiological activity and low REPIX values $(<0.6)$ indicate the presence of allochthonous FDOM, while values between 0.6 and 1 suggest low presence of autochthonous FDOM [49]. Calculations where performed in Matlab2015b as previously described [48], (Eq. (1)).

\subsection{Solid-phase extraction and FT-ICR-MS analysis}

DOM was solid-phase extracted from filtered and acidified samples with commercially available PPL columns (100 mg, Agilent, USA) [50]. Cartridges where precleaned and conditioned with methanol and MilliQ water. After extraction of the sample DOM, cartridges were rinsed with acidified ultrapure water ( $\mathrm{pH} 2, \mathrm{HCl} 25 \%$, p.a., Carl Roth, Germany), dried with argon gas and eluted with $950 \mu \mathrm{l}$ of methanol (MS-grade,
Sigma-Aldrich, USA). Extraction efficiencies on a carbon basis were 10 to $20 \%$ for M2 and 30 to $50 \%$ for M1 and M3. PPL columns have been previously evaluated to recover up to $62 \%$ of DOC in seawater samples [50], with very small and polar compounds exhibiting low extraction efficiencies [51]. We attribute the lower extraction efficiencies of M2 to the higher concentration of carbohydrates freshly produced by cyanobacteria [15]. In addition to the incubation extracts, an in-house reference sample extracted from North Equatorial Pacific Intermediate Water (NEqPIW) was analyzed seven times under the same conditions to control for instrument variability and to serve as a reference for refractory deep ocean DOM [15]. The mass spectra were obtained on a 15T Solarix FT-ICR-MS (Bruker Daltonics, USA) equipped with an electrospray ionization source (Bruker Apollo II) applied in negative mode. Methanol extracts were diluted $1: 1(\mathrm{v} / \mathrm{v})$ with ultrapure water to yield a concentration of $10 \mathrm{mg} \mathrm{C} \mathrm{L}^{-1}$. The sample was injected at a flow rate of $120 \mu \mathrm{L} \mathrm{h}^{-1}$ with the capillary voltage set to $4 \mathrm{kV}$. 500 scans were coadded in a scanning range of 152-2000 Da. The spectra were internally mass calibrated with a list of known compounds using the Bruker Daltonics Data Analysis software package and processed using in-house Matlab routines. Molecular formulae were assigned according the rules published in [29]. The number of assigned molecular formulae, average intensity-weighted molecular masses, double bond equivalents (DBE), $\mathrm{H} / \mathrm{C}$ ratios and $\mathrm{O} / \mathrm{C}$ ratios (Supplementary Table S2) were calculated for each sample. Molecular formulae were assigned to molecular classes as described previously [27]. It has to be noted that this assignment is not unambiguous as one molecular formula may comprise many different isomers. Average intensity-weighted double bond equivalent (DBE) and modified aromaticity index (AImod) were calculated for each sample [29,52].

\subsection{Statistical analysis}

Excitation emission matrices were analyzed to characterize the photodegradation of the in situ produced FDOM with PARAFAC [41]. Principal components were validated via split half analysis using the DrEEM toolbox. A model explaining $>99.5 \%$ of the dataset variability was fitted for both irradiated and dark incubations; PARAFAC was performed in Matlab2015b [53,54]. Variable associations were determined with the non-parametric Spearman rank test and statistical significance was determined at a threshold of $p<.05$. Classification of the correlation coefficient $(\rho)$ used in this study was very strong $(\rho=0.9-1)$, strong ( $\rho=0.5-0.9)$, moderate weak $(\rho=0.3-05)$, very weak $(\rho<0.3)$. Analysis of variance (ANOVA) was performed in Microsoft Excel 2010. BrayCurtis dissimilarity was calculated to quantify differences between treated mescosms. The Bray-Curtis dissimilarity is expressed as a number between 0 and 1; where values near to 0 indicate low dissimilarity and values close to 1 indicated high dissimilarity. Bray-Curtis coefficients were multiplied by 100 and treated as percentages.

\section{Results and discussion}

\subsection{Modification of fluorescent spectra after irradiation}

The recorded EEMs were normalized to Raman units (RU) and the location of the main fluorophore peaks [47] are indicated through pairs of excitation/emission (EX/EM) wavelengths (Fig. 1). Irradiated EEMs for samples in mesocosms M1L, M2L and M3L showed typical photobleaching profiles of FDOM, meanwhile slight changes in the fluorescent intensity were observed for the control samples M1D, M2D and M3D (Figs. 1, 2, and 3).

After the third day (Fig. 1, M1L3), the irradiated samples exhibited a decrease of $50 \%$ in the intensity of their fluorescent signature. At day 18 , fluorophores in the region matching humic $\mathrm{A}(\mathrm{EX} / \mathrm{EM}=250 / 390 \mathrm{~nm})$ and Marine humic $\mathrm{M}(\mathrm{EX} / \mathrm{EM}=300 / 380)$ peaks were bleached and a fluorophore re-appeared in the region matching the tyrosine-like fluorophore $(E X / E M=276 / 306 \mathrm{~nm})$ with a fluorescent intensity of 

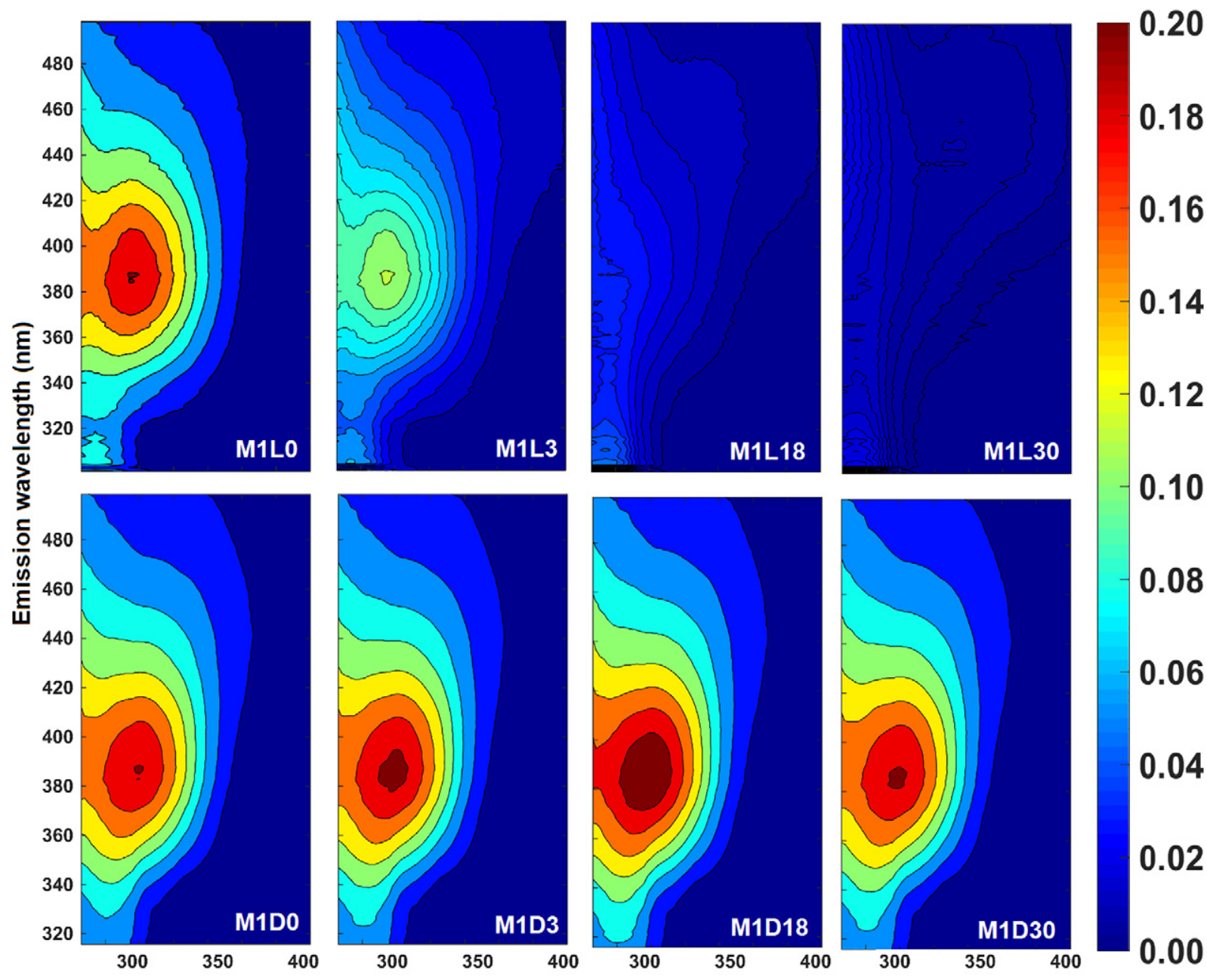

Excitation wavelength $(\mathrm{nm})$

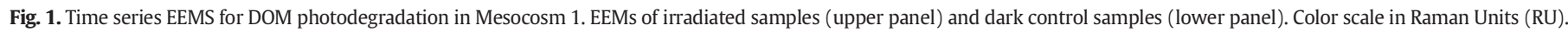

0.07 RU. At the end of the experiment (day 30), only two fluorophores remained in the regions matching to recently produced Marine humic C with an intensity of 0.020 RU and tyrosine-like (peak B) with an intensity of $0.025 \mathrm{RU}$. The appearance and variation of the intensity for this fluorophore is consistent with the presence of bacteria in the samples, and it might be associated to the exudates of secondary metabolites released into the surrounding medium [23]. In the dark control, the fluorescent intensity appeared to be quite stable over time, and a loss of intensity in the tyrosine-like region was recorded along our experiment. As it was reported previously, tyrosine-like compounds may exhibit short residence times due to the presumably rapid uptake by microorganisms [23].

The fluorescent intensity signature for the light incubation of M2 decreased between days 0 and 3. $>60 \%$ of the fluorescent intensity in the region matching with peak $\mathrm{C}$, equivalent to $0.12 \mathrm{RU}$, was lost due to photobleaching (Fig. 2). This is in agreement with a previous report, suggesting that a decrease in fluorescence of samples exposed to UV radiation for extended periods of time is achieved in the first hours of the exposure [55]. After day 3, a new fluorophore with an intensity of 0.05 RU was detected (Fig. 2, M2L3) in the region matching the tyrosinelike peak.

At the end of the experiment on day 30, three regions were distinguishable in the EEMs: tyrosine-like (peak B), visible marine humic (peak C) and bacterial produced-humic substances (peak M). This finding suggests that although UV irradiation leads to the photodegradation of DOM in M2, it also enabled reprocessing of in situ produced FDOM in the irradiated samples.

The fluorescent fingerprint of the M2 dark control remained quasiconstant until day 18 when intensity slightly increased from 0.14 to $0.16 \mathrm{RU}$ in the region matching the marine humic peak M (Fig. 2, M2D18, M2D30). Toward the middle of the experiment the intensity of peak $\mathrm{C}$ showed an increase from 0.10 and $0.12 \mathrm{RU}$ in the dark control; also the intensity of the peak B slightly increased from 0.06 to $0.085 \mathrm{RU}$ suggesting the reuse of DOM by microorganisms in both treatments. The use of DOM by bacteria was noted earlier and was assumed to be facilitated by the photolysis of DOM involving the production of low molecular weight compounds [14].

The decrease of fluorescent intensity in the light incubation M3 is consistent with a photobleaching pattern (Fig. 3). A predominant peak in the region matching to tyrosine-like (peak B) with an intensity of $0.10 \mathrm{RU}$ was recorded from day 3 to 18 , showing a decrease in intensity at day 30. It is interesting to note that toward the end the experiment the initial fingerprint for the FDOM appears to be restored, but with a decrease of $50 \%$ in the intensity. A closer look into the M3 initial spectrum composition, specifically at the region of humic A and humic $\mathrm{M}$ peaks showed that they were slightly displaced to the red part of the spectra at the end of the experiment (Fig. 3, M3L0, M3 L30). Previous studies have related a red shifted peak maximum for excitation and emission wavelength to the presence of compounds containing chemical substituents as hydroxyl $\left({ }^{-} \mathrm{OH}\right)$, alkoxyl ( $\left.\mathrm{R}-\mathrm{CHOH}\right)$, amino groups 


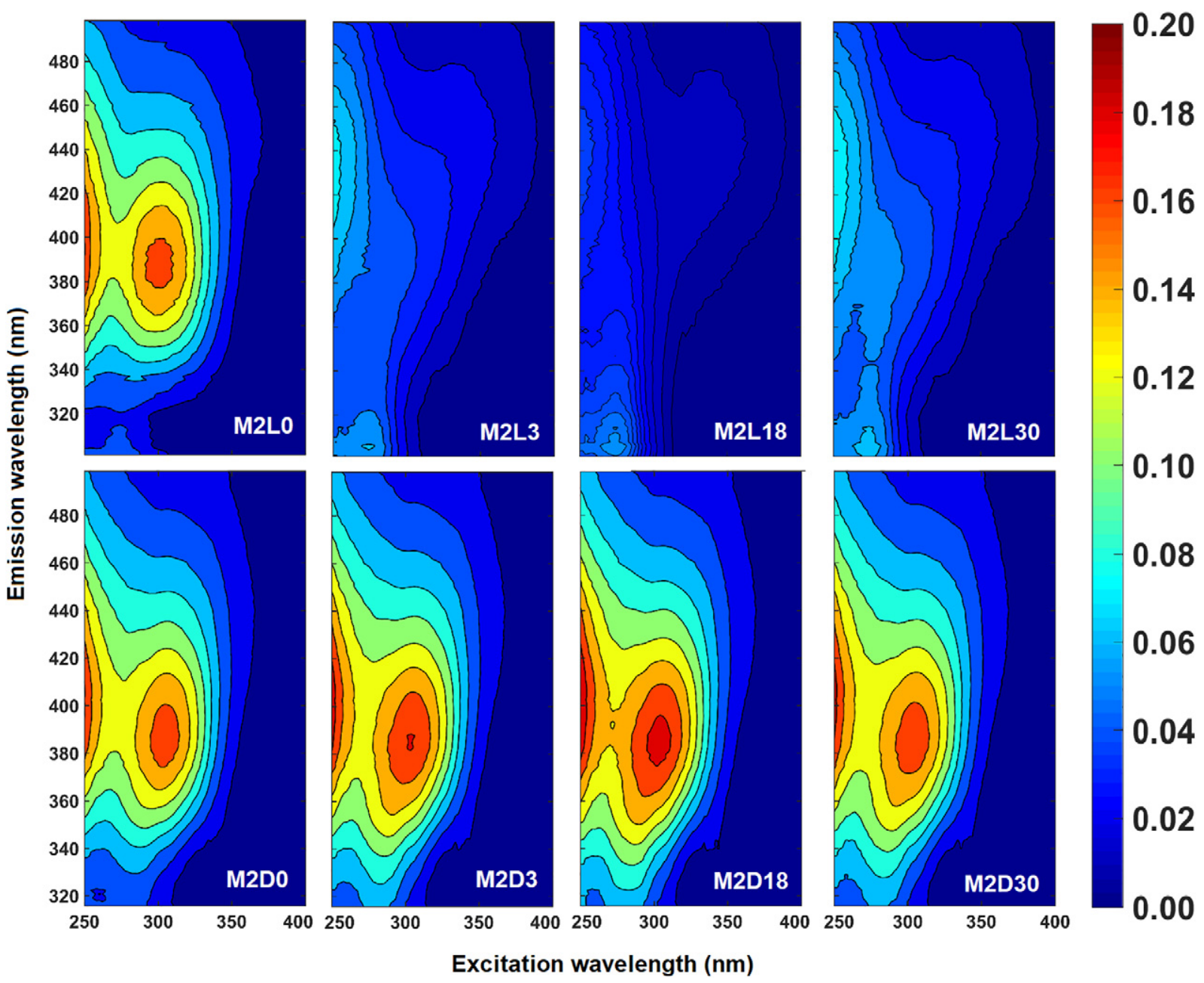

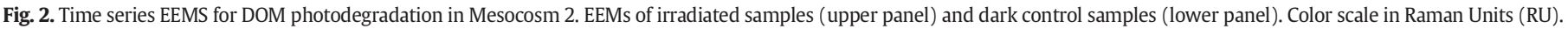

$\left(\mathrm{R}-\mathrm{NH}_{3}\right)$, and carboxyl $\left(\mathrm{R}-\mathrm{COO}^{-}\right)$constituents [56]. The fluorescent fingerprint of the dark incubation of $\mathrm{M} 3$ remained rather constant, with changes in the fluorescent intensity in the region matching to tryptophan-like substances indicating that the predominant processing in the dark control is due to biological activity in the samples.

Overall, a loss in the fluorescent fingerprint occurs in the regions related to humic compounds (peak C-like and humic M-like). This region is known to be associated to the presence of condensed molecules like bacterial and algal exudates [57-59]. Slight changes observed in the spectral region related to tyrosine- and tryptophan-like compounds suggest an active release and uptake of those compounds that could be associated with the presence of microorganisms and the quality of the initial DOM composition [60]. Osterholz et al. reported a convergence of DOM molecular composition for the first experimental phase of $>1000$ days of incubation without UV irradiation for the solid-phase extractable fraction [15]. They observed, however, high DOC concentrations especially in M2 (Table 1), attributed to a different microbial community presumably largely consisting of Synechococcus, producing nonextractable DOM of different composition compared to M1 and M3.

\subsection{Profiles of DOC and slope coefficient}

We found no significant differences for the DOC concentration between treatments (ANOVA, $N=6, p<.05$ ), (Table 1). This observation suggests a quasi-conservative behavior throughout the experiment.

Although no significant change in the DOC concentration was recorded, a high variability in the $\mathrm{S}_{275-295}$ was observed. Although no significant change in the DOC concentration was recorded, a high variability in the $\mathrm{S}_{275-295}$ was observed. This observation agrees with recent finding where great variability in $S_{275-295}$ was shown during the photodegradation of estuarine waters in tropical regions from different seasons [61]. This pattern projected with the appearance of a peak maximum toward the end of the experiment in the irradiated samples, and around the middle of the experiment in the dark control samples (Fig. 4). The trend in $\mathrm{S}_{275-295}$ suggests a mixed process which could include the photochemical breakdown of DOM in the irradiated samples.

The increase of $\mathrm{S}_{275-295}$ has been associated with the production of LMW DOM [40]. In our study, this observation can be associated to the photolysis of chemical compounds contained in DOM in the irradiated samples; meanwhile in the dark incubation the increase of the coefficient might indicate reprocessing of DOM by a small bacterial population present despite the intensive filtration protocol applied to the samples prior to incubation (Fig. 5). This microbial population exerted a direct influence on absorption coefficients and the fluorescent fingerprint of DOM.

Spearman rank test shows a negative correlation between bacterial cell numbers and the $S_{275-295}$ for the irradiated samples in M1. We observed that, although variable bacterial abundances were recorded within the samples $\left(<2.5 \times 10^{-3}\right.$ cells $\left.\mathrm{mL}^{-1}\right)$, in the irradiated samples photobleaching of freshly produced DOM limited the increase of $S_{275-}$ 295. This phenomenon is reported as the main driver for the decrease of the absorption coefficients [40]. Highest cell numbers for the lightexposed mesocosms were found at day 11 in M3, which showed a slightly different pattern regarding the photo-bleaching of the DOM 


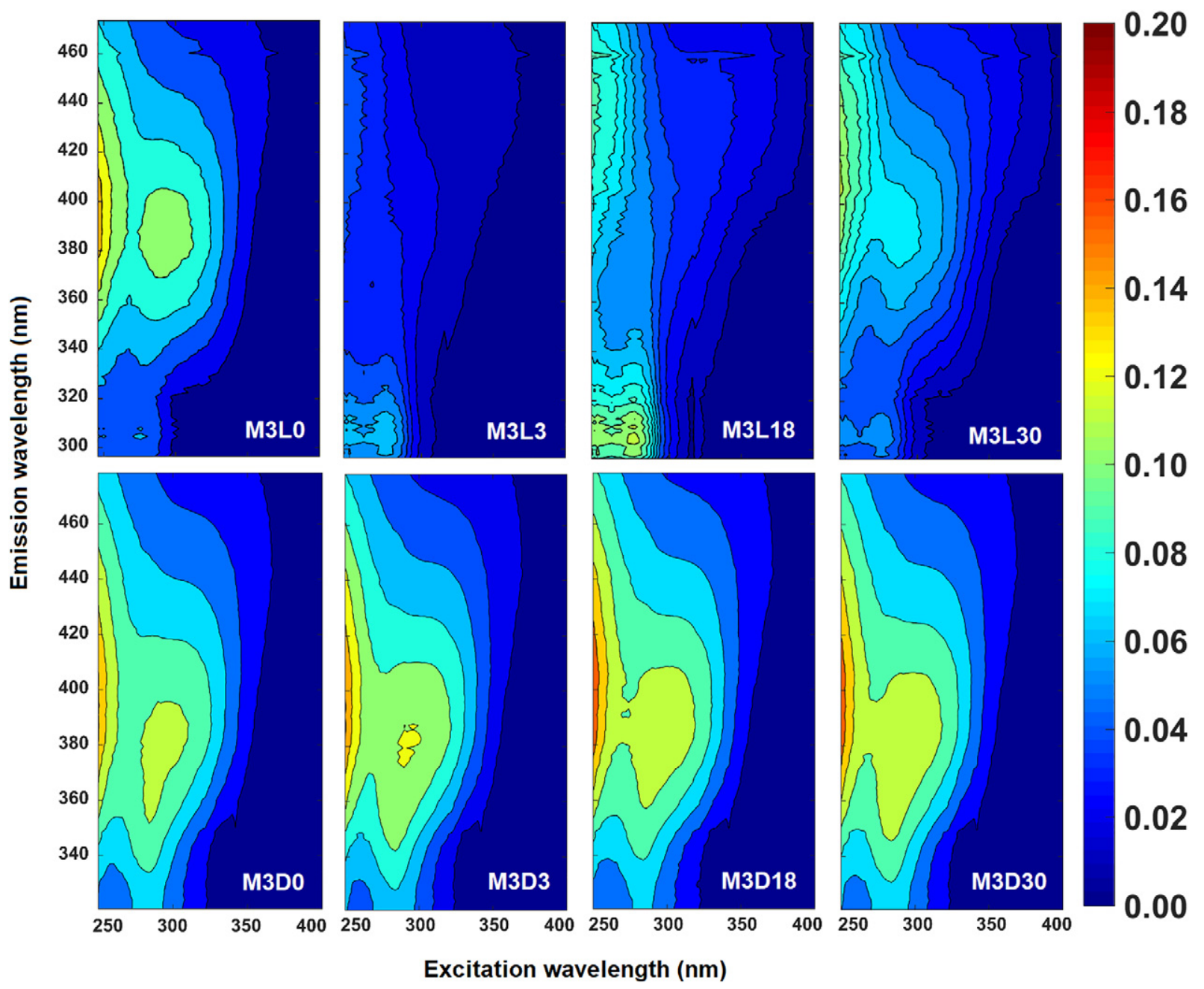

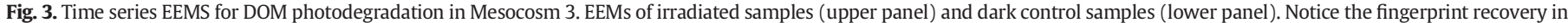
the irradiated sample at the end of the experiment. Color scale in Raman Units (RU).

components revealed by EEMs analysis (Fig. 3, M3L0, M3L30). Previous studies show that photodegradation of DOM compounds might serve as a source of carbon and energy to microorganisms [23]. As the bacterial community was found to diverge during the last phase of the original incubation [15], it is feasible that different bacteria survived the filtration procedure and found favorable growth conditions in the UV irradiation setup. This finding might therefore imply that here the bacterial population was involved in a different way compared to the other mesocosms in shaping the FDOM in the course of the experiment (Table 2).

Table 1

Dissolved organic carbon concentration $\left(\mu \mathrm{mol} \mathrm{L}^{-1}\right)$ in mesocosm treatments over the time of the incubation; s.d. denotes standard deviation.

\begin{tabular}{|c|c|c|c|c|c|c|}
\hline \multirow[t]{2}{*}{ Sampling day } & \multicolumn{2}{|c|}{ Mesocosm 1} & \multicolumn{2}{|c|}{ Mesocosm 2} & \multicolumn{2}{|c|}{ Mesocosm 3} \\
\hline & Light & Dark & Light & Dark & Light & Dark \\
\hline 0 & 202 & 202 & 1046 & 1046 & 249 & 249 \\
\hline 3 & 212 & 227 & 1101 & 1105 & 265 & 272 \\
\hline 7 & 216 & 217 & 1097 & 1092 & 263 & 259 \\
\hline 11 & 220 & 225 & 1103 & 1100 & 264 & 260 \\
\hline 18 & 205 & 230 & 1061 & 1109 & 251 & 284 \\
\hline 30 & 219 & 213 & 1076 & 1068 & 274 & 252 \\
\hline Average & 212 & 219 & 1080 & 1087 & 261 & 263 \\
\hline s.d. & 6.78 & 9.60 & 21.63 & 22.72 & 8.67 & 11.93 \\
\hline F calculated & 0.2231 & & 0.2019 & & 0.0533 & \\
\hline F critical & 1.687 & & 0.6627 & & 0.8220 & \\
\hline
\end{tabular}

Spearman rank test result for M2 and M3 showed a positive correlation between bacterial cell numbers and the $S_{275-295}$. This trend might indicate that the production of LMW DOM under dark conditions is related to the bacterial abundance, and possibly to a reprocessing of DOM compounds. This observation is in agreement with previous reports stating that reprocessing of DOM by microorganisms is the preferential mechanism in dark environments [14].

\subsection{Modification of biogeochemical indices}

\subsubsection{Recent produced material index}

DOM photodegradation promotes rupture of chemical structures releasing LMW compounds under irradiation, but also microbial reprocessing of DOM can lead to the production of LMW compounds. As it was previously reported, fresh microbial LMW compounds are preferentially produced under dark conditions [40]. As a consequence, weak correlations are expected between bacterial cell numbers and REPIX under highly illuminated environments. In our study, negative to very weak correlations between the bacterial cell numbers and REPIX were recorded in all mesocosms under irradiation; the strongest positive correlations were recorded in the dark controls (Table 3 ). Strong correspondence between these two indicators was recorded in mesocosms 2 and 3; this trend is in agreement with the increase of the $S_{275-295}$, confirming the accumulation of LMW compounds in the dark control. 


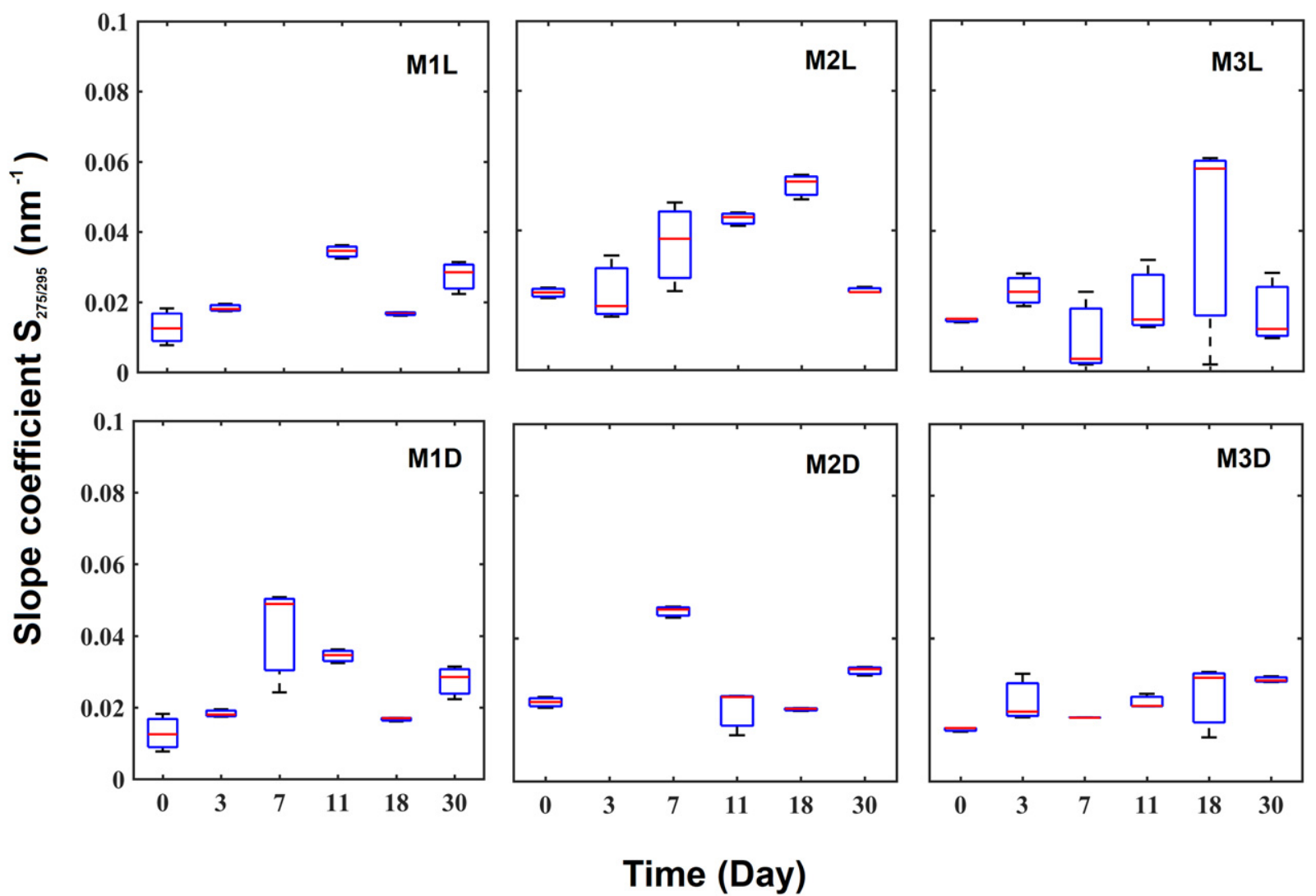

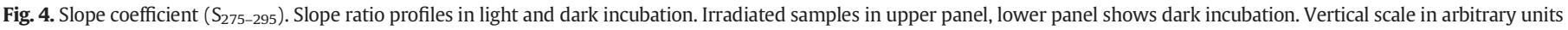
and horizontal scale in days. Note boxplots show triplicate analyses of the same sample. Data for samples M1LD7 and M2D3 is not available.

\subsection{PARAFAC analysis}

We identified three principal components in the light incubated samples. The components were labeled as: C1 (Peak M/ matching to marine humic like compounds, $\mathrm{C} 2$ (peak $\mathrm{C} /$ matching to bacterial humic substances), and C3 (peak B which corresponds to tyrosine-like compounds) (Supplementary Fig. S1). The PARAFAC analysis showed that the fluorescent intensity for certain fractions decreased with time. Specifically, humic M and humic C-like fractions seemed to be more photoreactive, while the intensity of tyrosine-like compounds showed a mixed behavior (Fig. 6).
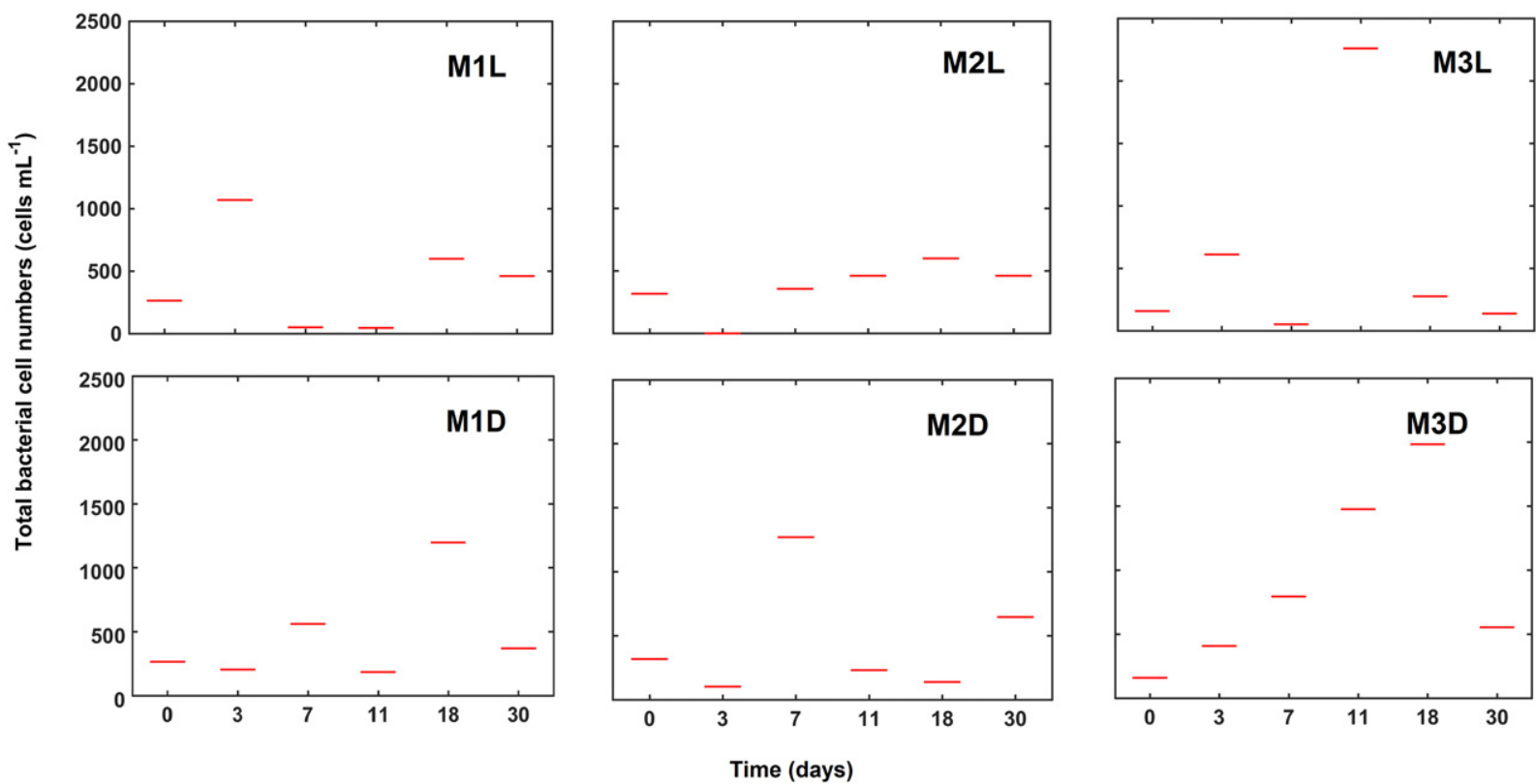

Fig. 5. Total bacterial cell numbers (cells $\mathrm{mL}^{-1}$ ) during light and dark incubation. Upper panel shows light incubation, while in lower panel is the dark incubation. 
Table 2

Spearman rank correlation between bacterial cell numbers and $\mathrm{S}_{275-295}\left(\mathrm{~nm}^{-1}\right)$. Calculation of rho $(p<.05, n=6)$, positive trends mainly found in the dark incubation. Results in bold are significant.

\begin{tabular}{lllllll}
\hline & M1L & M1D & M2L & M2D & M3L & M3D \\
\hline rho & -0.25 & 0.029 & 0.45 & $\mathbf{0 . 8 5}$ & 0.40 & $\mathbf{0 . 4 9}$ \\
Relation & Very & Very & Moderate & Strong & Moderate & Moderate \\
& weak & weak & weak & & weak & weak \\
$\mathrm{n}$ & 6 & $\mathbf{5}$ & 6 & $\mathbf{5}$ & 6 & $\mathbf{6}$ \\
\hline
\end{tabular}

A divergence in the fluorescent composition was recorded in the dark incubation of M3; instead of the component C3 tyrosine-like (peak B), we detected the component C4 tryptophan-like compound (peak T), (Supplementary Table S1). Main differences were found in the fluorescence intensity and relative position of the components detected in both treatments (Fig. 7).

The spectroscopic characterization of the PARAFAC components showed similarities between C3 and C4 (Fig. 7). Both components are related to microbiologically produced substances and protein residues, which is in agreement with the presence of a small bacterial population in the samples. It has to be noted that in comparison with the dark control, the emission peak was displaced to the red part of the spectra for the fluorophore peaks which match with marine humic $\mathrm{M}$ fractions and especially for the tyrosine-like peak. This positive displacement might indicate the photo-oxidation of the molecules in the light incubation and could be related to the biological reprocessing of the materials in the dark incubation, as was previously reported [62].

\subsection{DOM molecular characterization}

Molecular characterization of irradiated DOM was performed through the calculation of chemical indices based on molecular formulas attributed to FT-ICR-MS signals. Overall aromaticity accessed via the AImod showed a slight increase in the first three days followed by a constant decrease until day 17. A slight increase in the AImod was observed after day 17 in all mesocosms. The AImod values ranged between 0.220 and 0.185 denoting some decomposition of aromatic DOM molecular formulas. The average intensityweighted DBE decreased during the first 3 days of incubation. After this, an increase was recorded followed by a decreasing trend until day 30. DBE values ranged between 6.4 and 5.8 indicating in general a slight loss of the unsaturated character in the irradiated samples (Fig. 8).

The DBE and AImod were generally lower in the photodegraded samples and continued to diverge from the values recorded for the refractory deep sea DOM reference. The observed trends suggest that a transformation process took place instead of the production of refractory DOM. According to the DBE and AImod values we infer that the DOM signature did not become more similar to deep sea RDOM due to the continuous exposure to UV (Fig. 8). This can be related to the fact that only a small fraction of DOM absorption (240 to $390 \mathrm{~nm}$ ) was targeted by the UV-A 340 radiation (290 to $390 \mathrm{~nm}$ ). Additionally, taking into account the relative intensity of all assigned molecular formulas, we calculated the Bray-Curtis dissimilarity of

\section{Table 3}

Spearman rank correlation between the bacterial cell numbers and REPIX. Positive trends mainly found in the dark incubation. Classifiers are defined as very strong $(\rho=0.9-1)$, strong $(\rho=0.5-0.9)$, moderate weak $(\rho=0.3-05)$, very weak $(\rho<0.3)$. Results in bold are significant.

\begin{tabular}{lllllll}
\hline & M1L & M1D & M2L & M2D & M3L & M3D \\
\hline rho & 0.14 & 0.31 & 0.14 & $\mathbf{0 . 6 9}$ & -0.49 & $\mathbf{0 . 6 0}$ \\
relation & Very & Moderate & Very & Strong & Moderate & Strong \\
& weak & weak & weak & & weak & \\
n & 6 & 5 & 6 & 5 & 6 & 6
\end{tabular}

each sample to the seven NEqPIW analyses. Dissimilarity of the replicate NEqPIW analyses was $5.2 \pm 1.6 \%$, and overall dissimilarity of deep ocean refractory and irradiated DOM did not decrease over the course of the experiment (Fig. 9). Molecular group contributions were calculated for all mesocosms at each time point along the experiment. Here we present the results of Spearman rank test for selected groups describing those changes. A closer look into the chemical groups composition showed that DOM photodegradation produced intermediate metabolites with varying degrees of oxidation. In our study, specific groups such as polycyclic aromatics (PCA), polyphenols (POLY), highly unsaturated aromatic (HUAR) and highly unsaturated aliphatic (HUAL) were discriminated according to their elemental composition. The Spearman rank test between the bacterial cell numbers and relative contributions of the selected molecular groups showed for both, light and the dark incubation (Table 4). Under light incubation, a negative correlation between bacterial cell numbers and PCA molecular formula contribution was recorded. The trend might indicate a preferential use of (photodegraded) PCA compounds as a source of carbon under the experimental conditions. Additionally, we observed that the number of detected peaks slightly decreased in all treatments, suggesting a loss in molecular diversity (Supplementary Table S2).

We recorded a mixed tendency for the photolysis and biodegradation of POLY (Table 4). The Spearman rank test for the contrast between the bacterial cell numbers against POLY and HUAR molecular formulae showed a weak correlation under light incubation, while a weak positive trend was observed in the dark incubation. This observation indicates that HUAR were bleached from irradiated samples and accumulated in the dark controls. Furthermore, we recorded a strong positive correlation for the Spearman rank contrast between bacterial cell numbers and the HUAL in the irradiated mesocosms (Table 4). This observation can imply, as FT-ICR-MS is a relative method, either a release of HUAL compounds under light conditions possibly as by-product of complex molecules photolysis or an increase in HUAL contribution as more aromatic compound are photodegraded. The strong correlation between the bacterial cell numbers and the HUAL fraction indicates a positive contribution of the biodegradation to this trend. Spearman rank test showed an inverse correlation between bacterial cell numbers and the HUAL in the dark incubation. Bacterial cell numbers and HUAL were inversely correlated (Table 4). This trend suggests reprocessing of freshly produced DOM, specifically HUAL compounds, is a key driver of DOM transformation under dark conditions.

Spearman rank contrast between DBE and the PARAFAC components intensity (Supplementary Table S4) showed a positive strong correlation between the $\mathrm{C} 1$ (Marine humic $\mathrm{M}$ ) and $\mathrm{C} 2$ (Bacterial humic $\mathrm{C}$ like) in M1L. Although this correlation suggests that unsaturated compounds are associated with $\mathrm{C} 1$ and $\mathrm{C} 2$, the contrast did not show a clear trend for M2L and M3L. This observation can be attributed to not only the differences in the amount and quality of the DOM, but also to the presence of different microbial populations in the mesocosms.

The AImod was contrasted against the validated PARAFAC components. Following Supplementary Table S5, we found a positive correlation between the intensity of C1 (Marine humic) and C2 (Bacterial humic C-like) fractions against the AImod, which indicates that aromatic molecular formulae are associated to these two PARAFAC components. Our observations are consistent with previous data reporting similarities in the DOM quality and chemical composition of mesocosms M1 and M3 [15].

The comparison of the molecular and the PARAFAC composition of DOM has shown a positive correlation between DOM fractions and molecular groups in a previous study in the oligotrophic waters of the Mediterranean Sea. The authors report that molecules positively correlating with peak $\mathrm{C}$ were enriched in HUAR and depleted in polyphenols [32]. Similarly, in our study, we recorded strong positive correlations between the intensity of selected PARAFAC components in M1L and M3L 

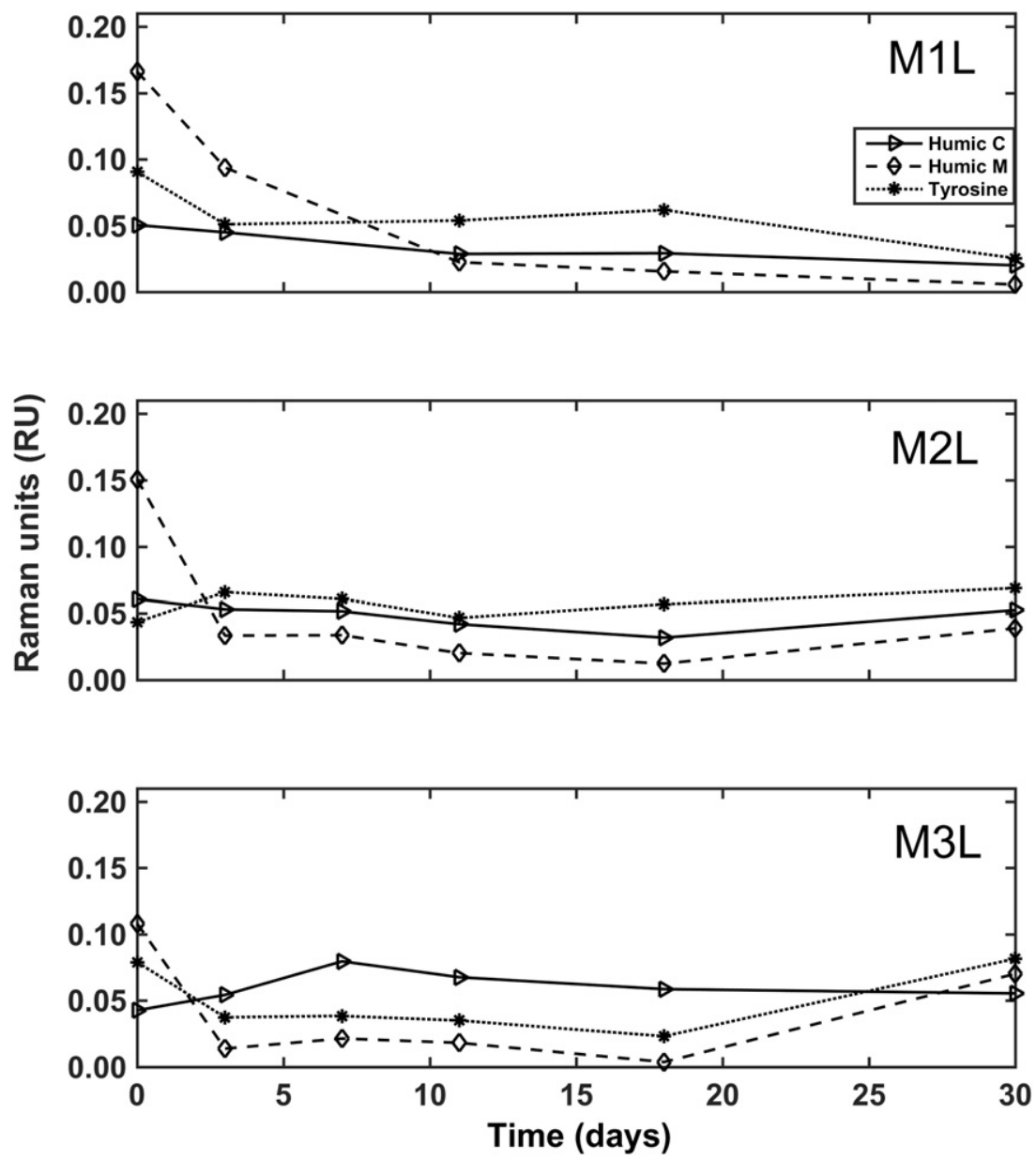

Fig. 6. Fluorescent intensity profile of PARAFAC main components over time. Notice the increase on the intensity of humic M and tyrosine toward day 30 in M3L.

and certain chemical classes. In M1L, we mainly observed PCA and POLY to be strongly positively correlated to humic $\mathrm{C}$ and humic $\mathrm{M}$ peaks. This finding is in agreement with the fact that humic substances are comprised of condensed materials to a high degree. Furthermore, we observed a strong positive trend between tyrosine-like peak $\mathrm{T}$ and HUAR. This finding suggests that under the experimental conditions, photobleaching of HUAR can be considered as a source of tyrosine-like compounds. The same pattern was observed in M3L, showing strong significant correlation between humic C-like fraction and PCA; for PCA we observed a significant correlation (Table 5 and Supplementary Table S3). This finding suggests that the relative contribution of some chemical groups (i.e. POLY, PCA) identified by FT-ICR-MS is at least partially reflected by the validated PARAFAC components (i.e. humic $\mathrm{C}$ and humic M).
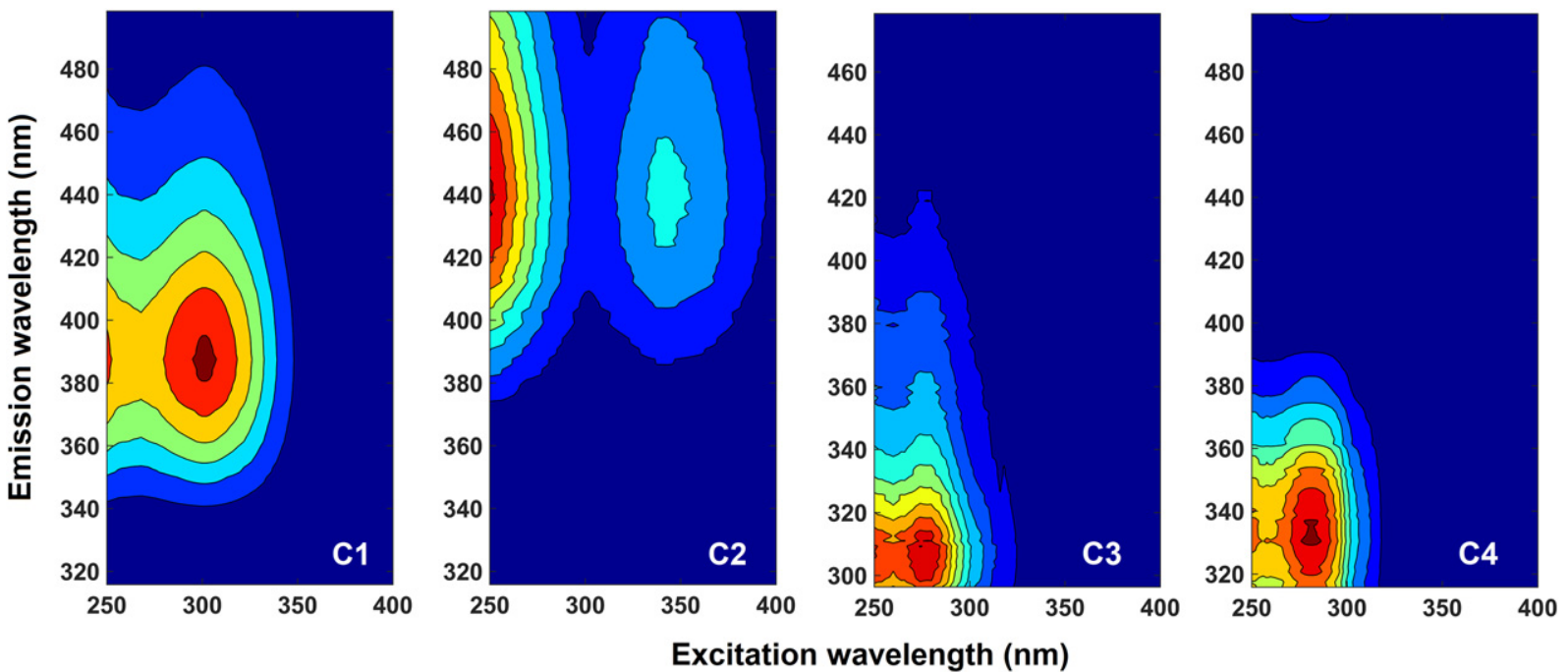

Excitation wavelength (nm)

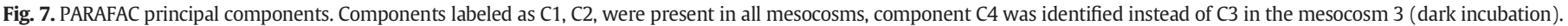



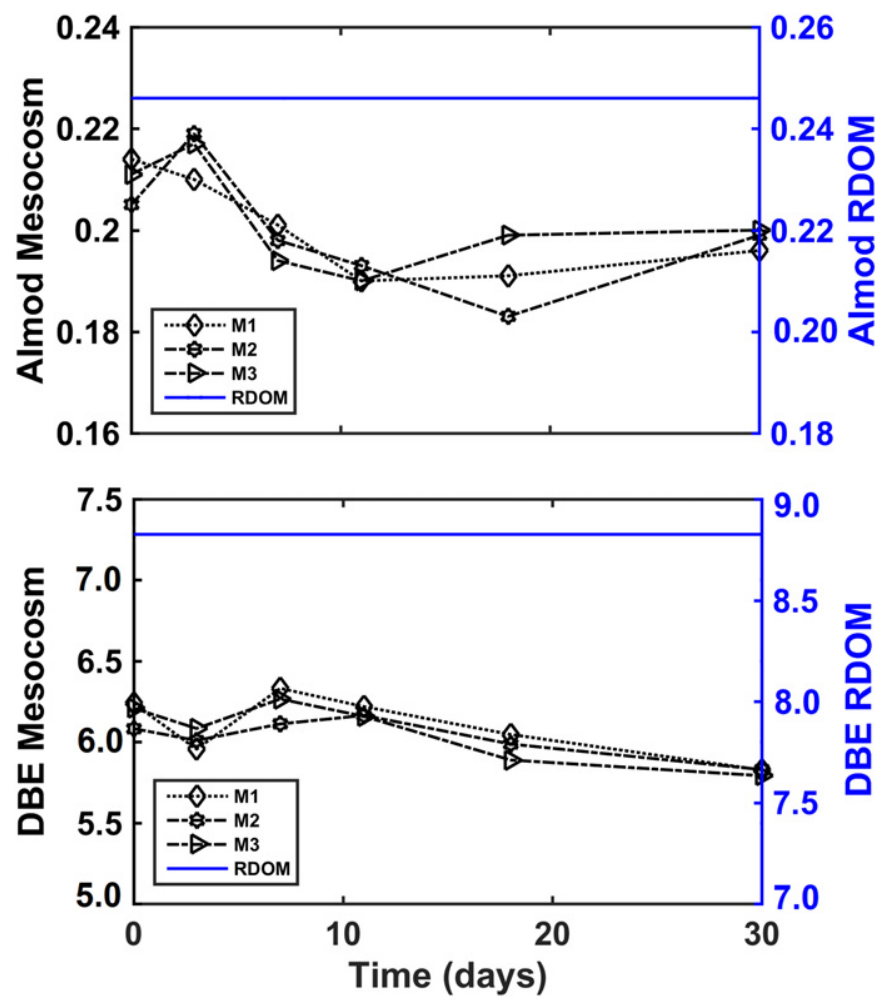

Fig. 8. DBE and AImod of SPE-DOM during UV irradiation. The blue line represents the average value in both cases determined for a deep sea RDOM reference $(n=7)$. Standard deviation for reference sample was below 0.0022 for AImod and 0.0032 for DBE.

\section{Conclusion}

The fluorescent fingerprint of freshly produced DOM from three mesocosms revealed a dynamic process under UV irradiation dominated by photobleaching. We observed that EEMs were efficiently bleached in the first $72 \mathrm{~h}$. The concentration of DOC remained constant throughout the experiment suggesting that changes observed on molecular level were small. Our findings indicated that even small microbiological populations can, by shaping and reprocessing new fluorophores, modify the

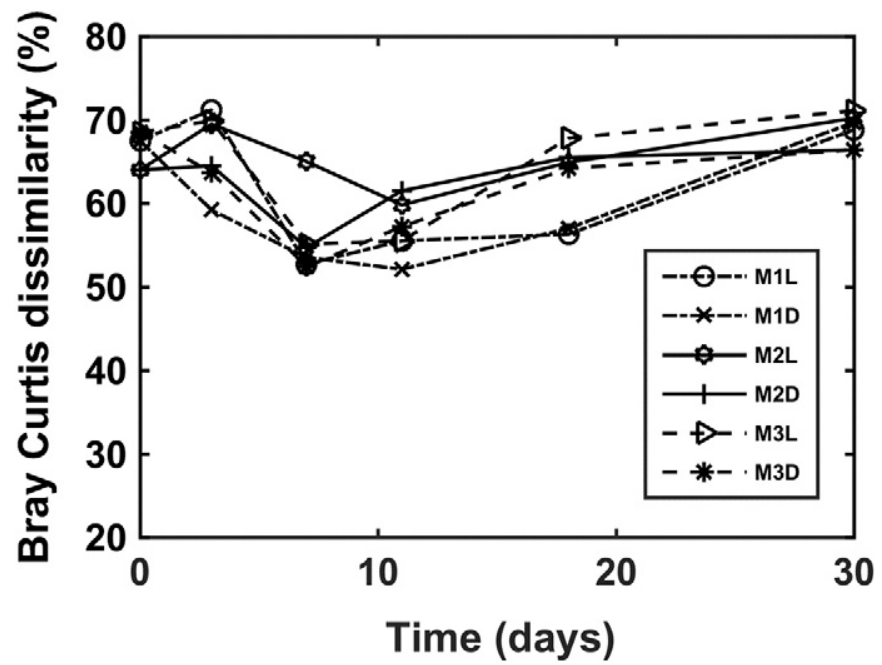

Fig. 9. Bray-Curtis dissimilarity of mesocosm DOM to seven replicate analyses of deep ocean refractory DOM (NEqPIW) over the course of the incubation experiment. Bray Curtis dissimilarity standard deviation was below $2.1 \%$.
Table 4

Spearman rank correlations for the contrast between bacterial cell numbers and relative contribution of chemical groups to SPE-DOM. PCA polycyclic aromatics; POLY pholyphenol-like; HUAR highly unsaturated aromatic; HUAL highly unsaturated aliphatic molecular formulas.

\begin{tabular}{llccr}
\hline Mesocosm & PCA & POLY & HUAR & \multicolumn{1}{c}{ HUAL } \\
\hline M1L & -0.314 & 0.229 & -0.429 & $0.657^{*}$ \\
M1D & -0.285 & 0.000 & 0.143 & -0.571 \\
M2L & -0.057 & 0.171 & 0.000 & 0.457 \\
M2D & -0.942 & -1.000 & $0.657^{*}$ & -0.486 \\
M3L & -0.257 & -0.029 & 0.229 & 0.629 \\
M3D & -0.257 & 0.114 & 0.286 & -0.543 \\
\hline
\end{tabular}

*Correlation is significant $(n=6, p<.05)$.

FDOM spectroscopic fingerprints while this effect was less apparent in DOM molecular composition derived from ultrahigh resolution mass spectrometry. Yet, the spectrofluorometric description through PARAFAC indicated that changes in the fluorescent intensities of main components were associated with specific chemical classes identified in DOM via FT-ICR-MS. For example, the average DBE and AImod strongly correlated to PARAFAC components $\mathrm{C} 1$ and $\mathrm{C} 2$ in at least one of the irradiated treatments. Through our integrative analysis, we could show that both the optical and mass spectrometric analyses with their different analytical windows applied in concert can provide very complementary tools to trace changes in DOM molecular composition under UV irradiation. However, taking into account compositional indices and the overall dissimilarity to refractory DOM, we infer that photochemical processing of recently biotically produced DOM does not constitute the main process responsible for the production of refractory DOM in the oceans.

Supplementary data to this article can be found online at https://doi. org/10.1016/j.saa.2020.118027.

\section{Funding}

M. L. Miranda acknowledges DAAD for the research scholarship (Forschungsstipendien für Doktoranden und Nachwuchswissenschaftler für mehr als 6 Monate, 2014/15, Number 57076385) and SENACYTIFARHU for the research scholarship (for Doctoral and Postdoctoral studies 2017/18, Program BIPD-2016). DFKI acknowledges financial support by the MWK through "Niedersachsen Vorab” (ZN3480).

\section{Contributions}

Contributed to conception and design: MLM, HO, TD, OZ.

Contributed to data acquisition: MLM, HO, HAG, PB.

Contributed to analysis and interpretation of data: MLM, HO, HAG, DT, OZ.

Drafted and/or revised the article: MLM, HO, HAG, PB, TD, OZ.

Approved the submitted version for publication: MLM, HO, HAG, PB, TD, OZ.

Table 5

Spearman rank correlation between PARAFAC components and main chemical groups identified after photodegradation.

\begin{tabular}{llcccc}
\hline Mesocosm & PARAFAC component & PCA & POLY & HUAR & HUAL \\
\hline M1L & Marine humic (C1) & 0.70 & 0.60 & 0.20 & -0.20 \\
& Humic C-like (C2) & 0.70 & 0.50 & 0.10 & -0.10 \\
& Tyrosine (C3) & 0.20 & -0.20 & 0.60 & -0.60 \\
M2L & Marine humic (C1) & -0.77 & -0.31 & -0.086 & 0.14 \\
& Humic C-like (C2) & -0.49 & -0.029 & -0.37 & 0.43 \\
& Tyrosine (C3) & -0.83 & -0.49 & -0.029 & -0.086 \\
M3L & Marine Humic (C1) & 0.60 & 0.54 & -0.20 & -0.029 \\
& Humic C-like (C2) & $0.89^{*}$ & 0.77 & -0.31 & -0.086 \\
& Tyrosine (C3) & 0.31 & 0.60 & 0.71 & 0.77 \\
\hline
\end{tabular}

${ }^{*}$ Correlation is significant $(n=6, p<.05)$. 


\section{Declaration of competing interests}

The authors declare that they have no known competing financial interests or personal relationships that could have appeared to influence the work reported in this paper.

\section{CRediT authorship contribution statement}

Mario L. Miranda:Conceptualization, Methodology, Data curation, Formal analysis, Validation, Visualization, Writing - original draft, Writing - review \& editing.H. Osterholz:Conceptualization, Methodology, Resources, Data curation, Formal analysis, Writing - review \& editing. H.-A. Giebel:Data curation, Formal analysis, Writing - review \& editing.P. Bruhnke:Data curation, Formal analysis, Writing - review \& editing.T. Dittmar:Funding acquisition, Project administration, Resources, Writing - review \& editing.0. Zielinski:Funding acquisition, Methodology, Project administration, Resources, Supervision, Validation, Visualization, Writing - review \& editing.

\section{Acknowledgments}

M.L. Miranda thanks Prof. Dr. Kathleen Murphy for the kind support with PARAFAC implementation and bug fixing, Dr. Rafael GonçalvezAraujo for PARAFAC advices. Matthias Friebe and Ina Ulber are thanked for support in the laboratory. Sincere thanks to Dr. Shungudzemwoyo Garaba and Elham Kamyab for commenting and proofreading. Authors are grateful to the two anonymous reviewers for their valuable comments and suggestions.

\section{References}

[1] D.A. Hansell, et al., Dissolved organic matter in the ocean: a controversy stimulates new insights, Oceanography 22 (4) (2009) 202-211.

[2] P. Coble, Marine optical biogeochemistry: the chemistry of ocean color, Chem. Rev. 107 (2007) 402-418.

[3] J. Para, et al., Fluorescense and absorption properties of chromophoric dissolved organic matter (CDOM) in coastal surface waters of the northwestern Mediterranean Sea, influence of the Rhône river, Biogeosciences 7 (2010) 4083-4103.

[4] M.D. McCarthy, J.I. Hedges, R. Benner, The chemical composition of dissolved organic matter in seawater, Chem. Geol. 107 (1993) 503-507.

[5] M.D. McCarthy, J.I. Hedges, R. Benner, Major biochemical composition of dissolved high molecular weight organic matter ins seawater, Mar. Chem. 55 (1996) 281-297.

[6] F.J. Stevenson, Humus Chemistry: Genesis, Composition, Reactions, John Wiley \& Sons, New York, 1994.

[7] O. Wurl, et al., Biofilm-like properties of the sea surface and predicted effects on airsea $\mathrm{CO}_{2}$ exchange, Prog. Oceanogr. 144 (2016) 15-24

[8] J.T.O. Kirk, Light and Photosynthesis in Aquatic Ecosystems, Third edition Cambridge University Press, New York, USA, 2011638.

[9] N.I.H. Mustaffa, M. Ribas-Ribas, O. Wurl, High-resolution variability of the enrichment of fluorescence dissolved organic carbon in the sea surface microlayer of an upwelling region, Elem Sci Anth 5 (2017) 52

[10] R. Benner, B. Biddanda, Photochemical transformations of surface and deep marine dissolved organic matter: effects on bacterial growth, Limnol. Oceangr. 43 (6) (1998) 1372-1378

[11] A.M. Kouassi, R.G. Zika, Light-induced destruction of the absorbance property of dissolved organic matter in seawater, Toxicol. Environ. Chem. 35 (3-4) (1992) 195-211.

12] M.L. Miranda, et al., Influence of solar radiation on biogeochemical parameters and fluorescent dissolved organic matter (FDOM) in the sea surface microlayer of the southern coastal North Sea, Elem Sci Anth 6 (1) (2018) 15.

[13] M.A. Moran, R.G. Zepp, Role of photoreactions in the formation of biologically labile compounds from dissolved organic matter, Limnol. Oceanogr. 42 (6) (1997) 1307-1316.

[14] K. Mopper, W.L. Stahovec, Sources and sinks of low molecular weight organic carbonyl compounds in seawater, Mar. Chem. 19 (4) (1986) 305-321.

[15] H. Osterholz, et al., Inefficient microbial production of refractory dissolved organic matter in the ocean, Nat. Commun. 6 (2015) 7422.

[16] D.A. Hansell, Recalcitrant Dissolved Organic Carbon Fractions, 2013.

[17] T. Dittmar, G. Kattner, Recalcitrant dissolved organic matter in the ocean: major contribution of small amphiphilics, Mar. Chem. 82 (2003) 115-223.

[18] T. Dittmar, Reasons behind the long-term stability of marine organic matter, in: D.A. Hansell, C.A. Carlson (Eds.), The Biogeochemistry of Marine Dissolved Organic Matter, Elsevier 2015, pp. 369-388.

[19] C. Lønborg, et al., Large stimulation of recalcitrant dissolved organic carbon degradation by increasing ocean temperatures, Front. Mar. Sci. 4 (436) (2018).

[20] J. Arrieta, et al., Response to Comment on "Dilution Limits Dissolved Organic Carbon Utilization in the Deep Ocean ", 350, 20151483.
[21] X. Zhou, K. Mopper, Photochemical production of low-molecular-weight carbonyl compounds in seawater and surface microlayer and their air-sea exchange, Mar. Chem. 56 (1997) 201-213.

[22] V. Lepane, T. Persson, M. Wedborg, Effects of UV-B radiation on molecular weight distribution and fluorescence from humic substances in riverine and low salinity water, Estuar. Coast. Shelf Sci. 56 (1) (2003) 161-173.

[23] S. Libes, The production and destruction of organic compounds in the sea, Introduction to Marine Biogeochemistry, Elsevier, USA 2009, pp. 394-422.

[24] R.M.W. Amon, R. Benner, Rapid cycling of high-molecular-weight dissolved organic matter in the ocean, Nature 369 (6481) (1994) 549-552.

[25] R. Benner, Chapter 3 - chemical composition and reactivity, in: D.A. Hansell, C.A. Carlson (Eds.), Biogeochemistry of Marine Dissolved Organic Matter, Academic Press, San Diego 2002, pp. 59-90.

[26] R.M. Cory, et al., Controls on dissolved organic matter (DOM) degradation in a headwater stream: the influence of photochemical and hydrological conditions in determining light-limitation or substrate-limitation of photo-degradation, Biogeosciences 12 (2015) 6669-6685.

[27] H. Osterholz, et al., Environmental drivers of dissolved organic matter molecular composition in the Delaware estuary, Front. Earth Sci. 4 (2016) 95.

[28] A. Stubbins, et al., Illuminated darkness: molecular signatures of Congo River dissolved organic matter and its photochemical alteration as revealed by ultrahigh precision mass spectrometry, Limnol. Oceanogr. 55 (4) (2010) 1467-1477.

[29] B.P. Koch, T. Dittmar, From mass to structure: an aromaticity index for highresolution mass data of natural organic matter, Rapid Commun. Mass Spectrom. 20 (5) (2006) 926-932.

[30] B.P. Koch, et al., Advanced characterization of marine dissolved organic matter by combining reversed-phase liquid chromatography and FT-ICR-MS, Mar. Chem. 111 (3-4) (2008) 233-241.

[31] R.L. Sleighter, P.G. Hatcher, The application of electrospray ionization coupled to ultrahigh resolution mass spectrometry for the molecular characterization of natural organic matter, J. Mass Spectrom. 42 (5) (2007) 559-574

[32] A.M. Martínez-Pérez, et al., Linking optical and molecular signatures of dissolved organic matter in the Mediterranean Sea, Sci. Rep. 7 (1) (2017) 3436.

[33] O.Zielinski, et al., Assessing fluorescent organic matter in natural waters: towards in situ excitation-emission matrix spectroscopy, Appl. Sci. 8 (12) (2018) 2685.

[34] E. Parlanti, et al., Dissolved organic matter fluorescence spectroscopy as a tool to estimate biological activity in a coastal zone submitted to anthropogenic inputs, Org. Geochem. 31 (2000) 1765-1781.

[35] P. Kowalczuk, et al., Characterization of chromophoric dissolved organic matter (CDOM) in the Baltic Sea by excitation emission matrix fluorescence spectroscopy, Mar. Chem. 96 (2005) 273-292.

[36] M.L. Miranda, et al., Spectroscopic evidence of anthropogenic compounds extraction from polymers by fluorescent dissolved organic matter in natural water, Journal of European Optical Society: Rapid Publications 11 (2016) 16014.

[37] N. Hudson, A. Baker, D. Reynolds, Fluorescence analysis of dissolved organic matter in natural, waste and polluted waters-a review, River Research Applied 23 (2007) 631-649.

[38] L. Galgani, A. Engel, Changes in optical characteristics of surface microlayers hint to photochemically and microbially mediated DOM turnover in the upwelling region off the coast of Peru, Biogeosciences 13 (2016) 2453-2473.

[39] R. Gonçalves-Araujo, et al., Using fluorescent dissolved organic matter to trace and distinguish the origin of Arctic surface waters, Sci. Rep. 6 (2016) 33978.

[40] J.R. Helms, et al., Absorption spectral slopes and slope ratios as indicators of molecular weight, source, and photobleaching of chromophoric dissolved organic matter, Limnol. Oceanogr. 53 (3) (2008) 955-969.

[41] K.R. Murphy, et al., Fluorescense spectroscopy and multi-way techniques, Parafac. Anal. Methods 5 (2013) 6557-6566.

[42] R. Bro, PARAFAC. Tutorial and applications, Chemom. Intell. Lab. Syst. 38 (2) (1997) 149-171.

[43] C.A. Stedmon, R. Bro, Characterizing dissolved organic matter fluorescence with parallel factor analysis: a tutorial, Limnol. Oceanogr. Methods 6 (11) (2008) 572-579.

[44] J.R. Helms, et al., Photochemical flocculation of terrestrial dissolved organic matter and iron, Geochim. Cosmochim. Acta 121 (2013) 398-413.

[45] H.-A. Giebel, et al., Complementary energy acquisition via aerobic anoxygenic photosynthesis and carbon monoxide oxidation by Planktomarina temperata of the Roseobacter group, FEMS Microbiol. Ecol. 95 (5) (2019).

[46] J. Rahlff, et al., High wind speeds prevent formation of a distinct bacterioneuston community in the sea-surface microlayer, FEMS Microbiol. Ecol. 93 (5) (2017) fix041.

[47] P. Coble, Characterization of marine and terrestrial DOM in seawater using excitation-emission matrix spectroscopy, Mar. Chem. 51 (1996) 325-346.

[48] V. Drozdowska, P. Kowalczuk, M. Jozefowicz, Spectrofluorometric Characteristics of Fluorescent Dissolved Organic Matter in a Surface Microlayer in the Southern Baltic Coastal Waters, 10, 2015 (2015).

[49] V. Drozdowska, et al., Study on organic matter fractions in the surface microlayer in the Baltic Sea by spectrophotometric and spectrofluorometric methods, Ocean Sci. 13 (2017) 633-647.

[50] T. Dittmar, et al., A simple and efficient method for the solid-phase extraction of dissolved organic matter (SPE-DOM) from seawater, Limnol. Oceanogr. Methods 6 (6) (2008) 230-235

[51] J. Raeke, et al., Selectivity of solid phase extraction of freshwater dissolved organic matter and its effect on ultrahigh resolution mass spectra, Environmental Science: Processes \& Impacts 18 (7) (2016) 918-927.

[52] B.P. Koch, T. Dittmar, From mass to structure: an aromaticity index for highresolution mass data of natural organic matter, Rapid Commun. Mass Spectrom. 30 (1) (2016) 250. 
[53] R. Jaffé, K.M. Cawley, Y. Yamashita, Applications of excitation emission matrix fluorescence with parallel factor analysis (EEM-PARAFAC) in assessing environmental dynamics of natural dissolved organic matter (DOM) in aquatic environments: a review, Advances in the physicochemical characterization of dissolved organic matter: impact on natural and engineered systems 1160 (2014) 27-73.

[54] Y. Shutova, et al., Spectroscopic characterisation of dissolved organic matter changes in drinking water treatment: from PARAFAC analysis to online monitoring wavelengths, Water Res. 54 (2014) 159-169.

[55] J.R. Helms, et al., Loss of optical and molecular indicators of terrigenous dissolved organic matter during long-term photobleaching, Aquatic Science 76 (2014) 353-373.

[56] Á. Andrade-Eiroa, M. Canle, V. Cerdá, Environmental applications of excitationemission Spectrofluorimetry: an in-depth review I, Appl. Spectrosc. Rev. 48 (1) (2013) 1-49.

[57] B.G. Fox, et al., The in situ bacterial production of fluorescent organic matter; an investigation at a species level, Water Res. 125 (2017) 350-359.
[58] A. Geller, Degradation and formation of refractory DOM by bacteria during simultaneous growth on labile substrates and persistent lake water constituents, Swiss Journal of Hydrology 47 (1) (1985) 27-44.

[59] N. Kawasaki, R. Benner, Bacterial release of dissolved organic matter during cell growth and decline: molecular origin and composition, Limnol. Oceanogr. 51 (5) (2006) 2170-2180.

[60] C. Lønborg, et al., Photochemical alteration of dissolved organic matter and the subsequent effects on bacterial carbon cycling and diversity, FEMS Microbiol. Ecol. 92 (5) (2016).

[61] L. Yang, et al., Seasonal changes in the chemical composition and reactivity of dissolved organic matter at the land-ocean interface of a subtropical river, Environ. Sci. Pollut. Res. 26 (24) (2019) 24595-24608.

[62] Á. Andrade-Eiroa, M. Canle, V. Cerdá, Environmental applications of excitationemission Spectrofluorimetry: an in-depth review II, Appl. Spectrosc. Rev. 48 (2) (2013) 77-141. 